\title{
Emission and Combustion Characteristics of Hydrogen in Vortex Flame
}

\author{
Mostafa Khaleghia*, Seyed Ehsan Hosseinia, Mazlan Abdul Wahida \\ ${ }^{a}$ High-Speed Reacting Flow Laboratory, Faculty of Mechanical Engineering, Universiti Teknologi Malaysia, 81310, UTM Johor Bahru, Johor, Malaysia \\ *Corresponding author: mostafa26_k@yahoo.com
}

\section{Article history}

Received :15 November 2013

Received in revised form :

1 December 2013

Accepted :18 December 2013

\section{Graphical abstract}

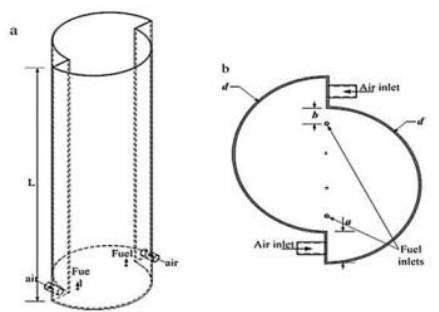

\section{Abstract}

Due to industrial development and population growth, global demand for energy has increased enormously. The increased consumption of primary sources of energy such as coal, oil and natural gas has exerted a strong influence on the atmospheric environment. Among all of the alternative fuels, hydrogen offers the greatest potential benefits to energy supply and the environment. In the current study computational investigations of a turbulent asymmetric vortex flame is presented. This study has predicted lean and stoichiometry flammability limits for hydrogen. The three dimensional flow fields have been described using a computational methodology that implements the $\mathrm{k}-\varepsilon$ RNG turbulence model. The computational model is validated for reaction flow. The special hydrogen-air mixing concept eliminates the risk of flame flashback and enables operation with very low $\mathrm{NO}_{\mathrm{x}}$ emissions.

Keywords: Hydrogen; vortex flame; turbulence model; nox emission

(C) 2014 Penerbit UTM Press. All rights reserved.

\subsection{INTRODUCTION}

Energy crisis and environmental issues have become the main concern of scientific communities nowadays. ${ }^{1,2}$ With a global focus on the reduction of fossil fuel consumption and harmful pollutant emissions, new technologies have been raised offering reduced emissions with the combustion of alternative and renewable fuels. ${ }^{3-7}$ Vortex combustion and the using of highly reactive fuels are two methods that have been shown to meet these challenges. ${ }^{8}$ In spite of increasing interest in the use of pure hydrogen $\left(\mathrm{H}_{2}\right)$ in combustion devices due to its unique features such as wide flammability limits and no carbon dioxide $\left(\mathrm{CO}_{2}\right)$ emissions, the inherently high reactivity and diffusivity of $\mathrm{H}_{2}$ are responsible for the potential of explosion hazards in storage. ${ }^{9,10}$ Regions of stable flame were found for large variations in hydrogen and air flow. Hydrogen-air diffusion flames were found to have a large region of stable operation compared to the hydrocarbons. Residual flames, lifted flames, and seated propagating flames were observed. ${ }^{11}$ High reactivity and diffusivity of $\mathrm{H}_{2}$ are responsible for the potential of explosion hazards in storage. The potential of $\mathrm{NH}_{3}$ as a carbon-free additive for improving the safety of $\mathrm{H}_{2}$ applied in both non premixed and premixed $\mathrm{H}_{2}$-air flames has been evaluated. ${ }^{12-15}$ An unconfined strongly swirled flow was investigated to study the effect of hydrogen addition on upstream flame propagation in a methaneair premixed flame using Large Eddy Simulation (LES) with a Thickened Flame (TF) model. The results show that the initiation of upstream flame propagation is associated with balanced maintained between hydrodynamics and reaction. ${ }^{16}$ The first discussion of vortex flames was reported in 1998 by Gabler. ${ }^{17}$ The turbulent vortex flame was described for the first time in such work by both experimental and computational methods. The major objective of Gabler's work was to identify the possible reduction in pollutant formation from vortex flames. A concise description of the flame anatomy was presented, and some of the basic features of vortex flames were reported. These features include the enhanced stability near to the lean flammability limit of the fuel, and some primary temperature profiling. The vortex flame of Gabler was created by injecting air through a tangential port in a cylindrical combustor. It was reported that such asymmetrically fueled flame has an increased range of stability compared to conventional swirl-stabilized flames, especially near to the lean equivalence ratio. Ultra reduced levels of $\mathrm{NO}_{\mathrm{x}}$ emission and extensive flame stability region were reported.

Computational Fluid Dynamics (CFD)-based numerical simulations have been performed to study the combustion of premixed hydrogen-air mixture in a series of chambers with same shape aspect ratio but various dimensions from millimeter to micron level. The effect of various heat transfer conditions at chamber wall, e.g. adiabatic wall, with heat loss and heat conduction within the wall, on the combustion is analyzed. These thermal conditions have strong effects on the combustion especially when the chamber dimension decreases and the ratio of surface area to volume become larger. ${ }^{18}$

Three combustion volumes have been analyzed for nonpremixed vortex combustion in meso-scale by $\mathrm{Wu} .{ }^{19}$ The hydrogen flammability limits for range of equivalence ratio between 0.25 for lean blow-off and 3-6 for rich limit were 
investigated. Chemical efficiencies were generally high exceeding $97 \%$ for hydrogen/air and $85 \%$ for methane/oxygen-enriched air. Zhou used premixed hydrogen and air by the high pressure tanks with high pressure reducing valves and analyzed the performance of catalytic micro combustors made of different materials. ${ }^{20}$ Flame stability in an annular heat recirculating micro combustor burning stoichiometric hydrogen-air mixture was explored by means of a rigorous thermal analysis. It was found that the lower flame stability limit is governed by thermal design of the micro combustor and inner tube prevented flame quenching at the lowest inlet velocities by maintaining heat recirculation to fuel-air mixture. This indicates that flame stability limit might be extended by enhancing the heat recirculating ability of the micro combustor. ${ }^{21}$ From the previous literature it can be noticed that no serious attempts were made to study the effects of using pure hydrogen on vortex flame in detail, hence, this has motivated the present study. In addition, most of the previous research on hydrogen as fuel focused on micro scale combustion and there is very limited data reported in the open literature that involved hydrogen in macro-combustion.

\subsection{COMBUSTOR CONFIGURATION}

In order to enhance the aerodynamics of vortex flames and create a strong vortex field for the flame stabilization, a novel concept of vortex combustor is presented and illustrated in Figure 1. This concept has two inlets for air and two inlets for fuel. The allocation of each pair of air and fuel inlets was designed to allow the mixing between fuel and air to occur in the vicinity of a strong forced vortex field. Such vortex is created by the introduction of the air with a full tangential velocity component to the asymmetric combustor. The dimensions of the experimental asymmetric vortex combustor built in our laboratory are: $a=20$ $\mathrm{mm}, \mathrm{b}=10 \mathrm{~mm}, \mathrm{~d}=110 \mathrm{~mm}$ and $\mathrm{L}=400 \mathrm{~mm}$. The fuel and air inlet nozzles were circular in cross section with a diameter of $2 \mathrm{~mm}$ and $5 \mathrm{~mm}$, respectively.

\subsection{COMBUSTION APPROACH}

A three dimensional, finite volume solver has been used to discretize the 3D flow domain through a second-order upwind scheme. Several triangular grids have been generated for the purpose of ensuring that the solution is grid-independent. The SIMPLE algorithm has been used to achieve the mass conservation between the pressure and velocity terms in the discretized momentum equation. Eddy-Dissipation algorithm has been chosen for turbulence-chemistry interactions. The operating pressure and temperature were set to 1 bar and $300 \mathrm{~K}$, respectively. The solution was considered converged when the residuals of each governing equation at consecutive iterations became less than $1 \times 10^{-3}$. At such condition, the flow field variables reached to stable local values with respect to any number of iterations. The equivalence ratio are $\varphi=1$ and $\varphi=0.5$, and the air mass flow rate and fuel mass flow rate for each equivalence ratio are, $0.0011 \mathrm{~kg} / \mathrm{s}, 3.21 \times 10^{-5} \mathrm{~kg} / \mathrm{s}$, respectively. The dimensions of the computational domain were similar to the full-scale actual dimensions of the asymmetric vortex combustor illustrated in Figure 2.
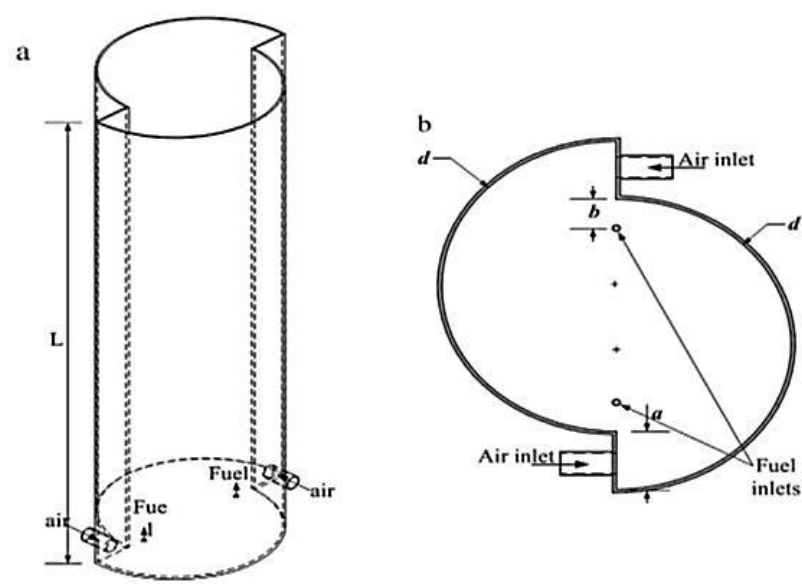

Figure 1 Schematic of the asymmetric combustor (a) Isometric view (b) Top view

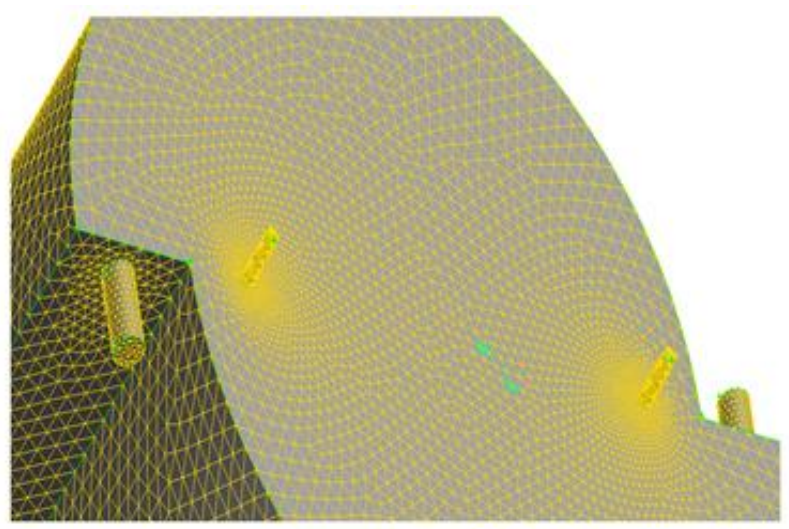

Figure 2 Schematic view of computational domain for the swirl injector

\subsection{GRID TESTING AND MODEL VALIDATION}

\subsection{Grid Independence Test}

A grid independence test was performed to evaluate the effects of grid sizes on the results as shown in Figure 3. Six sets of mesh were generated using triangular elements with 40,657 nodes, 83,179 nodes, 211,606 nodes, 375,534 nodes, 898,306 nodes and 1,415,488 nodes. Laminar flow with counter-flow configuration was considered for this test where the inlet air and fuel temperature were set to $300 \mathrm{~K}$. It was observed that the 375,534 nodes and 898,306 nodes produce almost identical results along the chamber with a percentage error of $0.54 \%$. Hence, a domain with 375,534 nodes was chosen to reduce the computing time. The summary of the grid independence test results is shown in Table 1. 


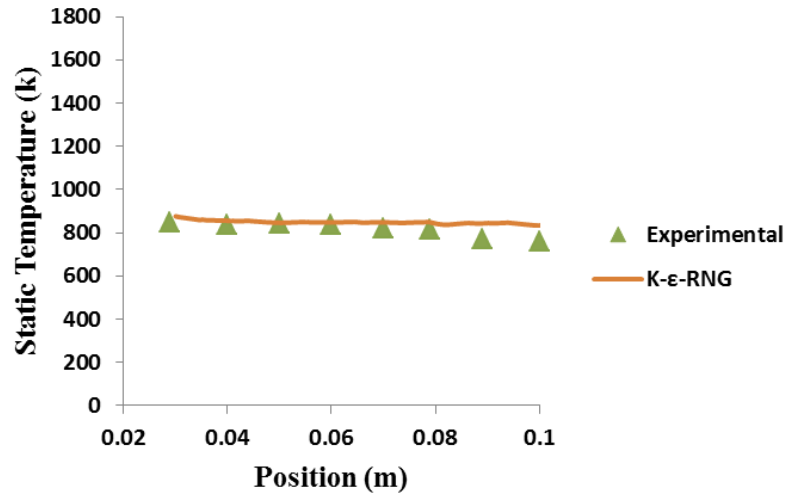

Figure 3 Comparison of the present results of central temperature profile along the chamber with the previous experimental result

Table 1 Grid independence test results

\begin{tabular}{|c|c|c|}
\hline Interval size & Nodes & Results \\
\hline 10 & 40657 & 曰 \\
\hline 7.5 & 83179 & $\mathbf{x}$ \\
\hline 5 & 211606 & 田 \\
\hline 4 & 375534 & $\square$ \\
\hline 3 & 898306 & $\nabla$ \\
\hline 2.5 & 1415488 & $\mathbf{x}$ \\
\hline
\end{tabular}

\subsection{Code Validation}

The model validation was done based on the geometry and boundary conditions which were used by Saqr. ${ }^{22}$ The simulation method has been compared with few related turbulent simulation work that has been performed in previous studies..$^{23,24,25,26,27}$ Air flows with a full tangential velocity component to the asymmetric combustor $(300 \mathrm{~K})$ and fuel flows coaxial with the center line $(300 \mathrm{~K})$. The mass flow rate for the air inlet set to $0.0011 \mathrm{~kg} / \mathrm{s}$ and the reacting case was performed at equivalence ratios of $\varphi=0.974$. It can be seen from Figure 3 that the temperature values fall between the accepted ranges for $\mathrm{k}-\varepsilon$ turbulence model.

\subsection{NUMERICAL RESULTS}

The effects of vortex flame on the flame temperature and emissions as well as the performance of the hydrogen as fuel are analyzed and discussed in this section.

\subsection{Characteristics of Hydrogen Combustion in Vortex Flame}

Predicted flame structure, including distribution of temperature flame and major species mass fractions, for non-premixed $\mathrm{H}_{2}$-air flames are shown in Figure 4, to illustrate the flame height and maximum temperature values. Two main points has been observed in analyzing these temperature profiles. The first is the flame height which is corresponding to the location of maximum temperature. The flame height is approximately $45 \mathrm{~mm}$. The second point is about the asymmetric structure of the flame. The temperature profiles in two perpendicular directions (i.e. $\mathrm{x}$ and $\mathrm{y}$ ) show different trends. Thus, the flame is shown to be asymmetric with respect to the radial and azimuthal directions.

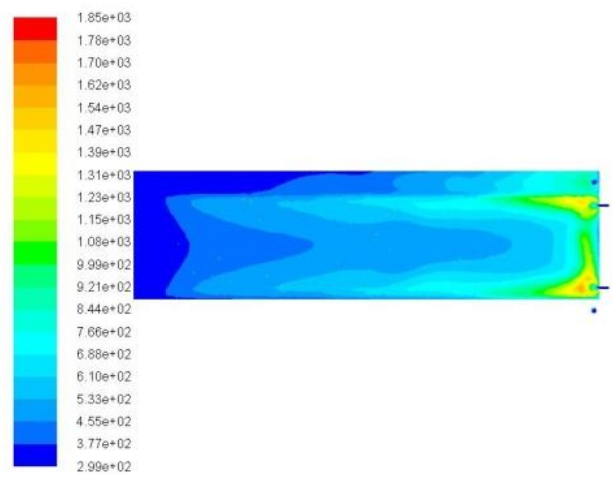

(a) Temperature (K) $\varphi=0.5$

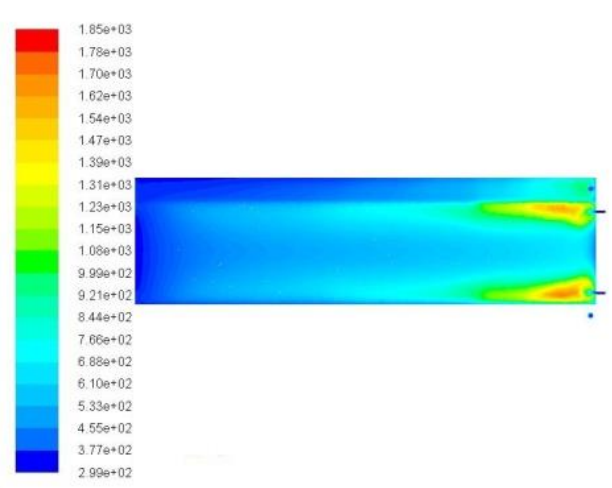

(b) Temperature (K) $\varphi=0.7$

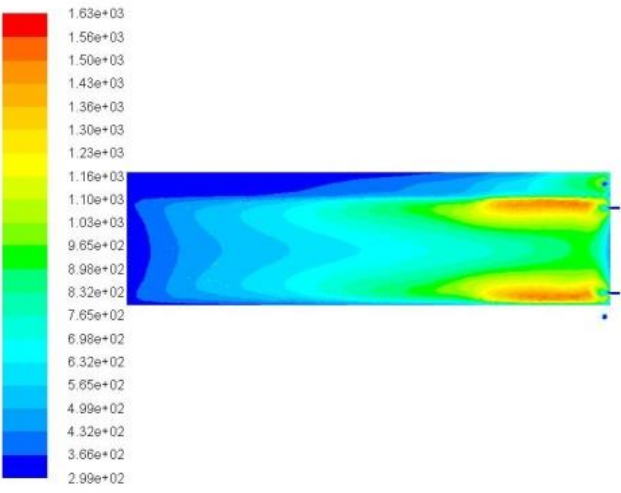

(c) Temperature (K) $\varphi=1$

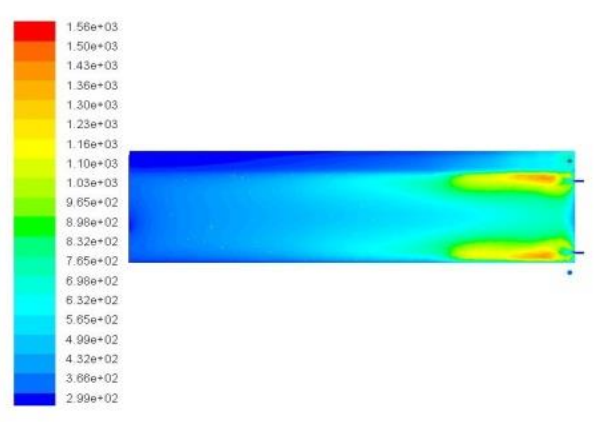

(d) Temperature (K) $\varphi=1.4$

Figure 4 Flame structure in various equivalence ratios 


\subsection{Flame Temperature}

The predicted central temperature profiles at two different equivalence ratios are plotted in Figure 5. The central combustor region does not contain a reacting mixture and maximum temperature is $1160 \mathrm{~K}(\varphi=0.5), 900 \mathrm{~K}(\varphi=1), 770 \mathrm{~K}(\varphi=1.4)$ and $700 \mathrm{~K}(\varphi=0.7)$. In the experiments of Gabler, the central region contained reacting mixture and that was emphasized by the temperature gradient, at which the maximum temperature was approximately $1400 \mathrm{~K}$ for lean condition. This is major difference between the former and the latter flames.

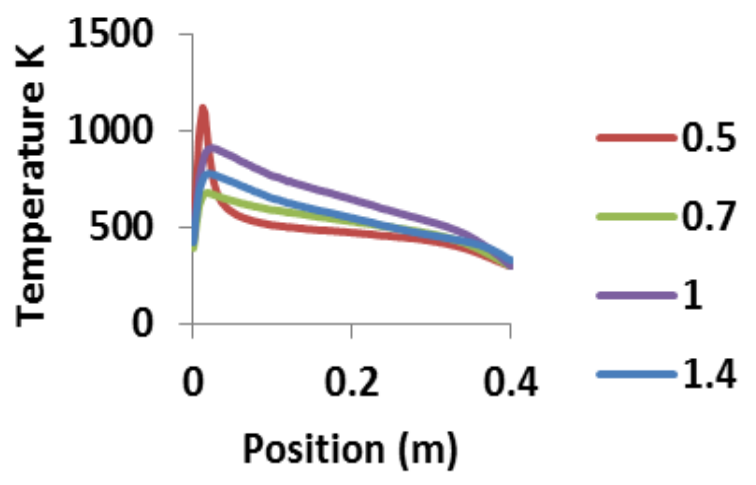

Figure 5 Variation of temperature along center axis of the combustor

\subsection{NO $_{x}$ Formation}

The nitrogen oxides emissions in the asymmetric vortex flame combustor by injection hydrogen as fuel are expected to be lower than other combustor design. This is due to the higher diffusivity and the lower inertia of hydrogen gas compared with methane, while methane - air mixing has higher $\mathrm{NO}_{\mathrm{x}}$ formation (Maximum NOx $=105 \mathrm{ppm}$ ). This reduces the local peak temperatures in the combustion chamber. Figure 6 demonstrates the counter of $\mathrm{NO}_{\mathrm{x}}$ formation in the chamber in stoichometric circumstances and Figure 7 shows the predict $\mathrm{NO}_{\mathrm{x}}$ emission in different equivalence ratio $\varphi=0.5,0.7,1,1.4$. As expected, it shows the effect of lean hydrogen combustion on $\mathrm{NO}_{\mathrm{x}}$ formation. It can be concluded that the lower $\mathrm{NO}_{\mathrm{x}}$ emissions of hydrogen in vortex flame are mainly attributed to the absence of excess oxygen.

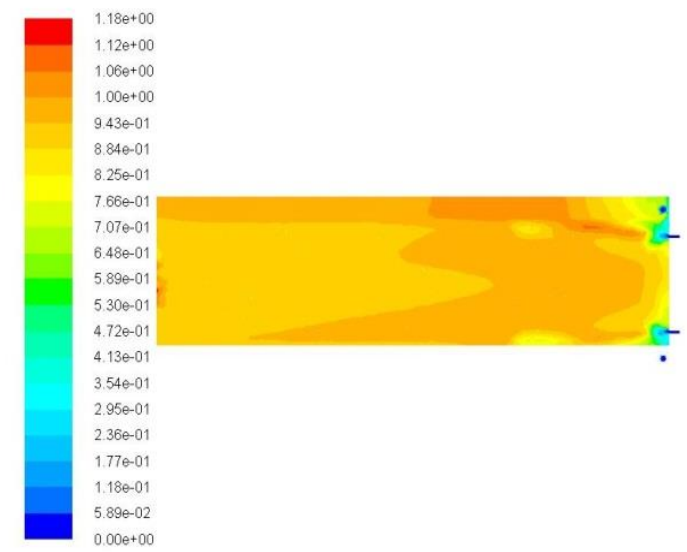

Figure $6 \mathrm{NO}_{\mathrm{x}}(\mathrm{ppm})$ for $\varphi=1$

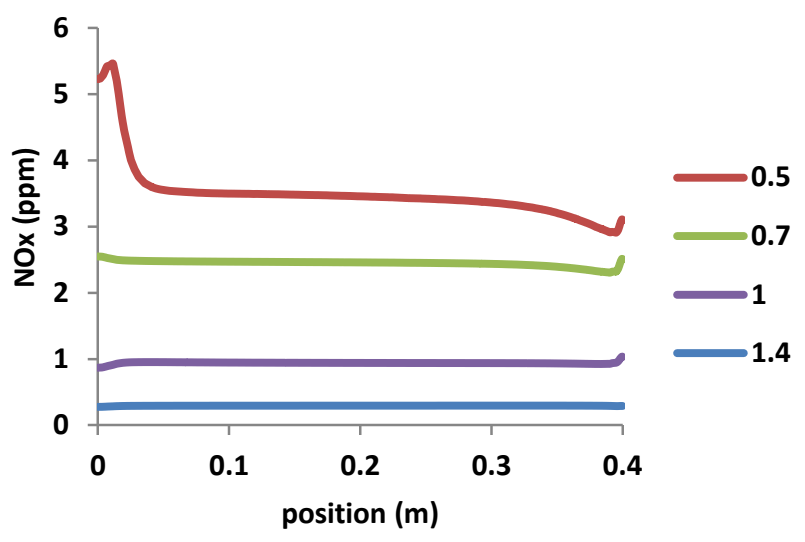

Figure $7 \mathrm{NO}_{\mathrm{x}}$ formation along the combustor at different equivalence ratios.

\subsection{CONCLUSION}

In this study, emissions and flame temperature of hydrogen combustion in four equivalence ratios were tested. CFD simulation was applied to investigate the combustion process. According to the results, their performances were completely differs from each other. The CFD simulation reveals that the difference of combustor performance was attributed to the change of equivalence ratio by using vortex flame mode. For low hydrogen content flames, the flame did not produce enough baroclinic torque, and the combined effects of gas-expansion and diffusion can stabilize the vortex flow and prevent upstream flame movement. The gas combustion and associated temperature influences the gas-expansion production. The vortex flame mechanism contributes to the net vorticity generation which produces considerable levels of negative axial velocity that favors upstream flame propagation.

\section{Acknowledgement}

The authors would like to thank Universiti Teknologi Malaysia for supporting this research activity under Research University Grant No.08J60 and Ministry of Science, Technology and Innovation of Malaysia for the EScience Grant No. 4S080.

\section{References}

[1] Hosseini, Seyed Ehsan, Amin Mahmoudzadeh Andwari, Mazlan A Wahid, and Ghobad Bagheri. 2013 A Review on Green Energy Potentials in Iran. Renewable and Sustainable Energy Reviews. 27: 533-545.

[2] Hosseini, Seyed Ehsan, Mazlan A. Wahid, and Nasim Aghili. 2013. The Scenario of Greenhouse Gases Reduction in Malaysia. Renewable and Sustainable Energy Reviews. 28: 400-409.

[3] Hosseini, S. E., Mazlan A. Wahid, and A. A. A. Abuelnuor. 2012. High Temperature Air Combustion: Sustainable Technology to Low Nox Formation. International Review of Mechanical Engineering. 6.5: 947953.

[4] Hosseini, Seyed Ehsan, Mazlan A. Wahid, and Abuelnuor Abdeen Ali Abuelnuor. 2012. Pollutant Reduction And Energy Saving In Industrial Sectors By Applying High Temperature Air Combustion Method. Int Rev Mech Eng. 6.7: 1667-1672.

[5] Hosseini, Seyed Ehsan, Saber Salehirad, Mazlan A. Wahid, Mohsin Mohd Sies, and Aminuddin Saat. 2012. Effect of Diluted and Preheated Oxidizer on the Emission of Methane Flameless Combustion. AIP Conference Proceedings. 1440.

[6] Hosseini, Seyed Ehsan, and Mazlan Abdul Wahid. 2012. Necessity of Biodiesel Utilization as a Source of Renewable Energy in Malaysia. Renewable and Sustainable Energy Reviews. 16.8: 5732-5740. 
[7] Hosseini, Seyed Ehsan, and Mazlan Abdul Wahid. 2013. Feasibility Study of Biogas Production and Utilization as a Source of Renewable Energy in Malaysia. Renewable and Sustainable Energy Reviews. 19: 454-462.

[8] Hosseini, Seyed Ehsan, and Mazlan Abdul Wahid. 2013. Biogas Utilization: Experimental Investigation on Biogas Flameless Combustion in Lab-scale Furnace. Energy Conversion and Management. 74: 426432.

[9] Mohammadi A, Shioji M, Nakai Y, Ishikura W, Tabo E. 2007. Performance and Combustion Characteristics of a Direct Injection SI Hydrogen Engine. Int J Hydrogen Energy. 32: 296-304.

[10] Antunes Gomes JM, Mikalsen R, Roskilly AP. 2009. An Experimental Study of a Direct Injection Compression Ignition Hydrogen Engine. Int $J$ Hydrogen Energy. 34: 6516-22.

[11] D. H. Uma, J. M. Joo b, S. Lee b, O. C. Kwon a. 2013. Combustion Stability Limits and NOx Emissions of Non-premixed Ammoniasubstituted Hydrogen-air Flames. International Journal of Hydrogen Energy. 38: 14854-14865.

[12] Lee, J. H., Lee, S. I., Kwon, O. C. 2010. Effects of Ammonia Substitution on Hydrogen/Air Flame Propagation and Emissions. Int $J$ Hydrogen Energy. 35: 11332-41.

[13] Lee, S., Kwon, O. C. 2011. Effects of Ammonia Substitution on Extinction Limits and Structure of Counter Flow Non-premixed Hydrogen/Air Flames. Int J Hydrogen Energy. 36: 10117-28.

[14] Joo, J. M., Lee, S., Kwon, O. C. 2012. Effects of Ammonia Substitution on Combustion Stability Limits and Nox Emissions of Premixed Hydrogen-air Flames. Int J Hydrogen Energy. 37: 6933-41.

[15] Lee, S. I., Um, D. H., Kwon, O. C. 2013. Performance of A Micro Thermo Photovoltaic Power System Using an Ammonia-hydrogen Blend-fueled Micro-emitter. Int J Hydrogen Energy. 38: 9330-42.

[16] De, A., \& Acharya, S. 2012. Dynamics of Upstream Flame Propagation in a Hydrogen-enriched Premixed Flame. International Journal of Hydrogen Energy. 37: 17294-17309.

[17] H. C. Gabler. 1998. An Experimental and Numerical Investigation of Asymmetrically- Fueled Whirl Flames, Princeton University.
[18] Hua, J., Wu, M., \& Kumar, K. 2005. Numerical Simulation of the Combustion of Hydrogen-air Mixture in Micro-Scaled Chambers. Part I: Fundamental Study. Chemical Engineering Science. 60(13): 3497-3506.

[19] Wu, M. H., Wang, Y., Yang, V., \& Yetter, R. A. 2007. Combustion in meso-scale vortex chambers. Proceedings of the Combustion Institute. 31(2): 3235-3242.

[20] Zhou, J., Wang, Y., Yang, W., Liu, J., Wang, Z., \& Cen, K. 2009. Combustion of Hydrogen-air in Catalytic Micro-Combustors Made of Different Material. International Journal of Hydrogen Energy. 34(8): 3535-3545.

[21] Jejurkar, S. Y., \& Mishra, D. P. 2011. Flame Stability Studies in a Hydrogen-Air Premixed Flame Annular Micro-Combustor. International Journal of Hydrogen Energy. 36(12): 7326-7338.

[22] Saqr, K., Turbulent Vortex Flames. 2011. Aerodynamics and Thermochemistry of Turbulent Confined Vortex Flames. Lambert Academic Publishing GmbH, November 2011.

[23] Khaleghi, M., Wahid, M. A., Sies, M. M., Saat, A. 2013. Investigation of Vortex Reacting Flows in Asymmetric Meso Scale Combustor. Applied Mechanics and Materials. 388: 246-25.

[24] Khalid M. Saqr, Hassan I. Kassem, Aly H. S., and Mazlan A. Wahid. 2012. Computational Study of Decaying Annular Vortex Flow using the $\mathrm{R}_{\varepsilon} / \mathrm{k}-\varepsilon$ Turbulence Model. Applied Mathematical Modelling. 36: 4652 4664

[25] Saqr, K. M., H. S. Aly, M. M. Sies, and Mazlan A. Wahid, Computational and Experimental Investigations of Turbulent Asymmetric Vortex Flames. 2011. International Communications in Heat and Mass Transfer. 38: 353-362.

[26] Saqr, K. M., H. S. Aly, H. I. Kassem, M. M. Sies, and M. A. Wahid. 2012. Computations of Shear Driven Vortex Flow in a Cylindrical Cavity Using a Modified k-e Turbulence Model. International Communications in Heat and Mass Transfer. 37(8): 1072-1077.

[27] Saqr, K. M., H. S. Aly, M. M. Sies, and Mazlan, A. Wahid. 2010. Effect of Free Stream Turbulence on NOx and Soot Formation in Turbulent Diffusion CH4-Air Flames. International Communications on Heat and Mass Transfer. 37(6): 611-617. 